\title{
Interactive comment on "Southern California
} margin benthic foraminiferal assemblages across a modern environmental gradient record recent centennial-scale changes in oxygen minimum zone" by Hannah M. Palmer et al.

Hannah M. Palmer et al.

hmpalmer@ucdavis.edu

Received and published: 12 February 2020

We thank the Associate Editor and Referee 1 for their helpful comments and suggestions to improve the manuscript. We have addressed each comment in the attached PDF, we have also included a PDF of updated Figure 3. 
Interactive

comment 


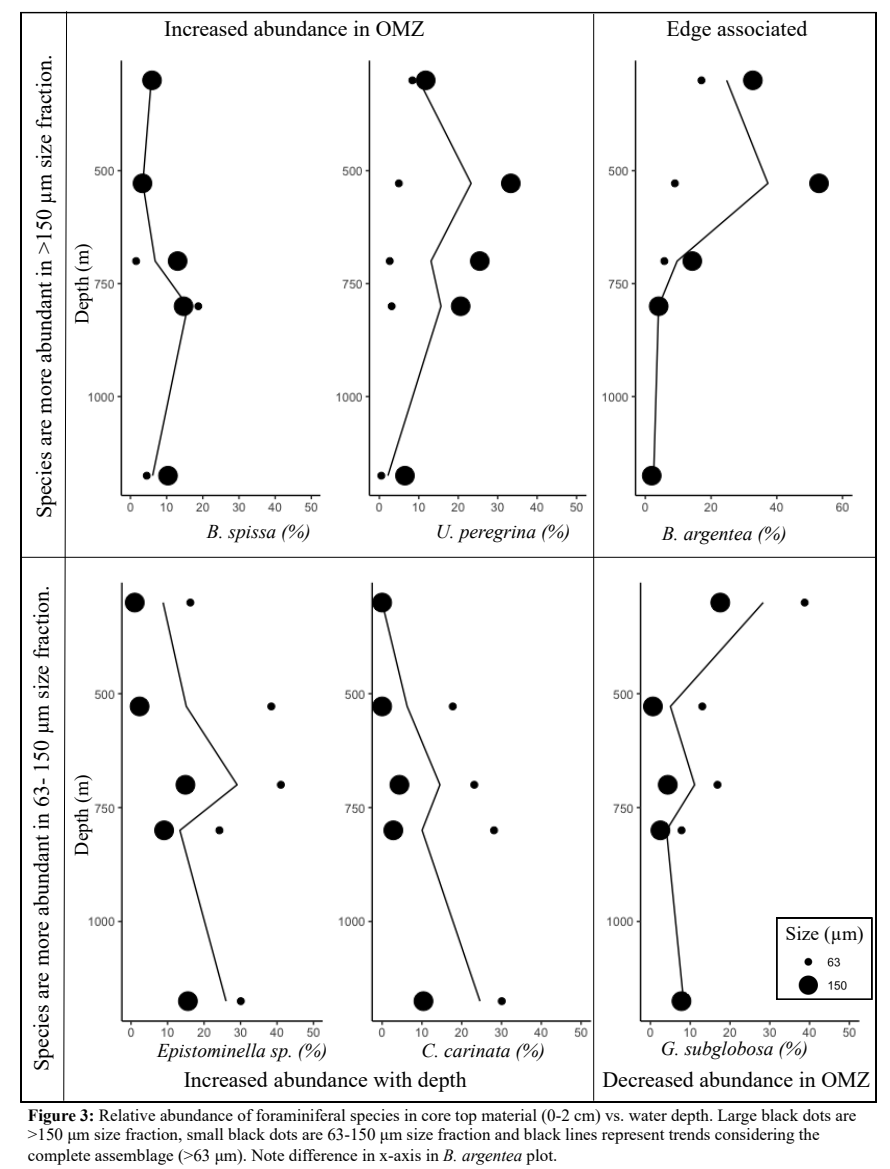

BGD

Interactive

comment

Printer-friendly version

Fig. 1. Updated Figure 3

Discussion paper 